\title{
Intrathecal dexmedetomidine-fentanyl for labor analgesia: randomized comparative study
}

Abbady A. Mohamed ${ }^{1}$ and Raafat A. Salem ${ }^{2^{*}}$

*Correspondence: rafaatsalem72@yahoo.com

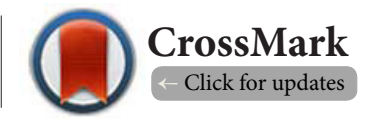

'Department of Anesthesiology, ICU and Pain Management, Qena Faculty of Medicine, South Valley University, Egypt.

${ }^{2}$ Sohag Faculty of Medicine, Sohag University, Egypt.

\begin{abstract}
Background: Fentanyl has been used along with bupivacaine for labor analgesia. Dexmedetomidine may be used to alleviate this pain because it has several analgesic properties, lack of respiratory depression and has a high placental retention. This study was aimed to evaluate the efficacy and safety of combination of IT dexmedetomidine and fentanyl on maternal and neonatal outcomes during labor in comparison to IT dexmedetomidine or IT fentanyl.

Patients and methods: 90 patients were included aged 19-39 years (ASA physical status I-II) with single uncomplicated pregnancy. Patients were randomly divided into three groups: group D: 30 patients were received IT $10 \mu \mathrm{g}$ dexmedetomidine in $1 \mathrm{ml}$ of normal saline, group F: 30 patients received IT $20 \mu \mathrm{g}$ fentanyl in $1 \mathrm{ml}$ of normal saline and group DF: 30 patients received IT $5 \mu \mathrm{g}$ dexmedetomidine plus $10 \mu \mathrm{g}$ fentanyl in $1 \mathrm{ml}$ of normal saline. Age, weight, height, parity, gestational age, rupture of membrane, cervical dilatation and progress of labor were noted. The time of onset, duration of analgesia, maternal parameters of heart rate (HR), mean arterial blood pressure (MAP) and Visual analog score (VAS) were recorded. Sideeffects of pruritus, nausea and vomiting, hypotension and bradycardia were recorded. Neonatal outcome in terms of mode of delivery, neonatal Apgar score and umbilical artery $\mathrm{pH}$ were recorded.
\end{abstract}

Results: The patient's demographics and labor characteristics were comparable among the studied groups. The dexmedetomidine group and dexmedetomidine and fentanyl mixture group have prolonged duration of analgesia. VAS score was improved in all groups after onset of analgesia. HR and MAP were lowest in dexmedetomidine group than other two groups. The fentanyl group showed significant increase in the adverse effect incidence (pruritus).

Conclusion: Addition of $5 \mu \mathrm{g}$ intrathecal dexmedetomidine to $10 \mu \mathrm{g}$ fentanyl prolonged the duration of analgesia. The combination decreases the incidence of side effects in comparison to IT $10 \mu \mathrm{g}$ dexmedetomidine or IT $20 \mu \mathrm{g}$ fentanyl alone.

Keywords: Dexmedetomidine, fentanyl, labour analgesia, neonatal

\section{Introduction}

Labor pain and painful uterine contractions cause hyperventilation and high catecholamine levels resulting in maternal and fetal hypoxemia [1]. Pain relief provides patient's comfort and attenuates the release of stress hormones [2]. Fentanyl has been used for labor analgesia extensively to decrease motor block of local anesthetics, however the addition of opioids to local anesthetics has disadvantages of pruritus and respiratory depression [3]. Dexmedetomidine is a highly selective a 2 adrenergic agonist which has both analgesic and sedative properties when used in combined with regional anesthesia [4]. Dexmedetomidine has an analgesic-sparing effect, significantly reducing opioid requirements and has a sympatholytic effect that can attenuate the stress response to surgery $[5,6]$. It can be titrated to the desired level of sedation so can be used as a sedative and adjuvant in anesthesia $[7,8]$. Dexmedetomidine used in pregnancy as it does not significantly cross the placenta due to its high placental retention [9]. Also it has no 
Mohamed et al. Journal of Anesthesiology \& Clinical Science 2015,

adverse effects on mother or fetus in many studies [10-12]. Our purpose was to evaluate the effect of combination of IT dexmedetomidine and fentanyl on maternal and neonatal outcomes during labor in comparison to IT dexmedetomidine or IT fentanyl.

\section{Patients and methods}

A prospective comparative study was done in obstetric and gynecological departments, Qena and Sohag university hospitals, South Valley and Sohag universities respectively, from January 2014 to December 2014. After approval of the local institutional ethical committee of South Valley and Sohag university hospitals, 90 patients were included aged 19-39 years (ASA physical status I-II) scheduled for normal vaginal delivery with uncomplicated pregnancy, cephalic presentation not in fetal distress, single fetus and in active labor (had 4 uterine contraction in $10 \mathrm{~min}$, each contraction lasted for 40-60 sec, cervical dilatation was 3-4cm or more and head engaged) were included in the study. Any patient with cardiac, liver, or kidney diseases, allergy to local anesthetics or study drugs, any contraindication of regional anesthesia, or patient refusal, intrauterine growth retardation or fetal compromise were excluded from this study. Written informed consent was taken from each patient.

This was prospective, randomized; comparative clinical study. Randomization and enrollment was done by closed envelop. Patients were randomly divided to three groups: group D: 30 patients received $5 \mu \mathrm{g}$ intrathecal dexmedetomidine in $1 \mathrm{ml}$ of normal saline; group F: 30 patients received IT $20 \mu \mathrm{g}$ fentanyl in $1 \mathrm{ml}$ of normal saline and group DF: 30 patients received IT $5 \mu \mathrm{g}$ dexmedetomidine plus $10 \mu \mathrm{g}$ fentanyl in 1 $\mathrm{ml}$ of normal saline.

All patients eligible for the study received $15 \mathrm{ml} / \mathrm{kg}$ Ringer's lactate solution intravenously. Aseptic precautions were taken. With the patient in the sitting position an intrathecal injection of the study drug was administered using a combined spinal epidural set (CSE) at L3-L4 intervertebral space. An epidural catheter was inserted $5 \mathrm{~cm}$ into the epidural space using the CSE set and secured for future administration of $10-12 \mathrm{ml}$ of $0.125 \%$ bupivacaine required when the VAS was recorded above 3 and repeated top-ups of the same dosage were administered as and when the VAS for pain was recorded above 3 till delivery of the baby. $10-15 \mathrm{ml}$ of $0.5 \%$ bupivacaine was administrated if emergency cesarean section was indicated.

\section{Data collection and measurements}

Hemodynamic data noninvasive blood pressure, heart rate, oxygen saturation, and respiratory rate were recorded. The obstetrician showed the cervical dilatation, stage and progress of labor, and fetal heart rate. The onset of administration of intrathecal analgesia was considered when the patient was in active labor. The baseline was defined as time before intrathecal injection of drugs. Analgesia onset was the time from intrathecal injection to time of recording a VAS less than 3. VAS was recorded thereafter every 1 minute for 10 minutes and then every 10 minutes till VAS reached more than 3 . Duration of analgesia was defined as the time from intrathecal injection to the time when VAS reached more than 3 and needed additional analgesia through the epidural catheter. Maternal heart rate and noninvasive blood pressure were recorded every $5 \mathrm{~min}$ following the intrathecal injection. Occurrence of hypotension which was defined as decrease in blood pressure more than $20 \%$ from baseline and bradycardia defined as heart rate less than 60 were immediately treated with intravenous fluids, ephedrine or atropine as appropriate. Fetal bradycardia was monitored by cardiotocograph and was initially treated by giving oxygen to mother and ensuring lateral position to avoid aortocaval compression. Other side effects such as pruritus, nausea and vomiting and respiratory depression were recorded pruritus was treated by i.v diphenhydramine $50 \mathrm{mg}$ and $10 \mathrm{mg}$ oral loratidine and nausea and vomiting were treated with ondansetron $4 \mathrm{mg}$. Modes of delivery were recorded. Neonatal outcome like; neonatal Apgar score and umbilical cord blood $\mathrm{pH}$ were recorded.

\section{Statistical analysis}

Statistical analysis was performed using the Statistical Package for the Social Sciences (SPSS) version 16.0 (IBM, Chicago, IL). A sample size of 26 patients in each group was determined through power analysis ( $\alpha=0.05 ; \beta=0.90)$ to detect a difference of $30 \mathrm{~min}$ in the time analgesia between groups. Data are presented as mean $\pm \mathrm{SD}$, or numbers as appropriate. Patient characteristics (age, weight, height, parity and gestational age), onset and duration of analgesia, APGAR score, and pH of umbilical artery were analyzed using the independent two sample t-test. Other parameters were studied using the Chisquare test or Fisher's exact test as appropriate. The linear mixed model was used for comparison of MAP and HR between the three groups. $P$ values of $<0.05$ were considered significant.

\section{Results}

A total of 90 laboring women accepted and participated throughout the study. The three groups, group D $(10 \mu \mathrm{g}$ dexmedetomidine alone), group F (20 $\mu \mathrm{g}$ fentanyl alone), and group DF ( $5 \mu \mathrm{g}$ Dexmedetomidine and $10 \mu \mathrm{g}$ fentanyl mixture) were comparable in terms of demographic variables and labor characteristics (Table 1).

Onset of analgesia was faster and duration of analgesia was longer in group DF than in the two other groups ( $p$-value $<0.001), 10$ patients in $D$ group, 13 patients in group $F$ and 9 patients in group DF needed top-ups of $10 \mathrm{ml}$ of $0.125 \%$ bupivacaine till delivery of baby. Regarding to maternal side-effects; hypotension and bradycardia were recorded in group D (6 patients (20\%), 3 patients (10\%) respectively) more than the two other groups; the fentanyl group showed significant increase in pruritus 11 patients (36\%); lastly nausea and vomiting were detected only in DF group 1 patient (3.3\%). The other side effects like shivering, respiratory depression 
Mohamed et al. Journal of Anesthesiology \& Clinical Science 2015, http://www.hoajonline.com/journals/pdf/2049-9752-4-1.pdf

Table 1. Demographic data, labor characteristics and fetal outcomes.

\begin{tabular}{|c|c|c|c|c|}
\hline & $\begin{array}{l}\text { Group D } \\
\mathbf{n}=30\end{array}$ & $\begin{array}{l}\text { Group F } \\
n=30\end{array}$ & $\begin{array}{l}\text { Group DF } \\
\mathbf{n}=\mathbf{3 0}\end{array}$ & $P$ value \\
\hline Age (year) & $25.72 \pm 4.30$ & $27.24 \pm 5.66$ & $26.00 \pm 5.05$ & $>0.05$ \\
\hline Weight (Kg) & $85.88 \pm 6.97$ & $84.44 \pm 5.16$ & $86.68 \pm 6.39$ & $>0.05$ \\
\hline Height $(\mathrm{Cm})$ & $163.36 \pm 6.95$ & $166.68 \pm 6.58$ & $165.52 \pm 5.93$ & $>0.05$ \\
\hline Parity & $\begin{array}{l}0-3 \\
\text { Primigravida(5) }\end{array}$ & $\begin{array}{l}0-3 \\
\text { Primigravida }(4)\end{array}$ & $\begin{array}{l}0-3 \\
\text { Primigravida(6) }\end{array}$ & $\begin{array}{l}>0.05 \\
>0.05\end{array}$ \\
\hline Gestational age (weeks) & $39.40 \pm 1.04$ & $39.72 \pm 1.10$ & $39.56 \pm 1.04$ & $>0.05$ \\
\hline \multicolumn{5}{|l|}{ Labor characteristics } \\
\hline Rupture of membrane (n, \%) & $11(36.6 \%)$ & $11(36.6 \%)$ & $14(46.6 \%)$ & $>0.05$ \\
\hline Cervical dilatation $(\mathrm{Cm})$ & $3.72 \pm 0.73$ & $4.04 \pm 0.78$ & $4.00 \pm 0.76$ & $>0.05$ \\
\hline Progress of labor $(\mathrm{cm} / \mathrm{h})$ & $1.6 \pm 0.4$ & $1.8 \pm 0.4$ & $1.7 \pm 0.3$ & -- \\
\hline Induced labor (n, \%) & $14(46.6 \%)$ & $11(36.6 \%)$ & $11(36.6 \%)$ & $>0.05$ \\
\hline Onset of analgesia (min) & $4.48 \pm 0.69$ & $4.20 \pm 1.11$ & $3.04 \pm 0.78$ & $<0.05^{\mathrm{bc}}$ \\
\hline Duration of analgesia (min) & $130.36 \pm 16.85$ & $110.96 \pm 13.87$ & $143.80 \pm 11.95$ & $<0.05^{\mathrm{abc}}$ \\
\hline $\begin{array}{l}\text { Number of patients needed } \\
\text { epidural analgesia }(n, \%)\end{array}$ & $10(30 \%)$ & $13(33.3 \%)$ & $9(43.3 \%)$ & $>0.05$ \\
\hline \multicolumn{5}{|l|}{ Fetal outcome } \\
\hline $\begin{array}{r}\text { Apgar score; at } 1 \text { minute } \\
\text { at } 5 \text { minute }\end{array}$ & $\begin{array}{l}7.76 \pm 0.8 \\
9.5 \pm 0.7\end{array}$ & $\begin{array}{l}7.80 \pm 0.8 \\
9.5 \pm 0.6\end{array}$ & $\begin{array}{l}7.84 \pm 0.9 \\
9.5 \pm 0.7\end{array}$ & $\begin{array}{l}>0.05 \\
>0.05\end{array}$ \\
\hline Umbilical artery $\mathrm{pH}$ & $7.27 \pm 0.05$ & $7.26 \pm 0.04$ & $7.28 \pm 0.04$ & $>0.05$ \\
\hline \multicolumn{5}{|l|}{ Adverse events } \\
\hline Hypotension (n, \%) & $6(20 \%)$ & $1(3.3 \%)$ & $3(10 \%)$ & $<0.05^{\mathrm{ab}}$ \\
\hline Bradycardia (n, \%) & $3(10 \%)$ & $1(3.3 \%)$ & $2(6.6 \%)$ & $>0.05$ \\
\hline Nausea or Vomiting (n, \%) & $0(0)$ & $0(0)$ & $1(3.3 \%)$ & $>0.05$ \\
\hline Pruritus (n, \%) & $0(0)$ & $11(36.7 \%)$ & $2(6.6 \%)$ & $<0.05^{\mathrm{abc}}$ \\
\hline
\end{tabular}

Group-D: Dexmedetomidine group; Group F: Fentanyl group;

Group-DF: Dexmedetomidine-fentanyl group

Values are mean $\pm \mathrm{SD}$ or number and percentage as appropriate. $\mathrm{p}<0.05^{\mathrm{a}}=$ significance difference between group $\mathrm{D}$ and group $\mathrm{F}$. $\mathrm{p}<0.05^{\mathrm{b}}=$ significance difference between group $\mathrm{D}$ and group DF. $\mathrm{p}<0.05^{\mathrm{c}}=$ significance difference between group $\mathrm{F}$ and group $\mathrm{DF}$. $\mathrm{p}>0.05=$ no significant differences between groups.

or postdural puncture headache were not noticed in the 3 study groups. Apgar scores (at 1 and 5 minutes) and mean umbilical artery $\mathrm{pH}$ in all the groups were within normal values with no significant differences between the groups $(P>0.05)$ (Table 1). There is no statistical difference between the three groups as regard the mode of delivery (Table 2). All patients in the three groups had baseline VAS ranged from 7-10, at 5 minutes reading VAS became less than 3 in the three groups and reached the lowest level (0-1) at 30 minutes reading and started to increase in the next readings (Figure 1). VAS became more than 3 earlier in the group $F$ than group $D$ and group DF.

\section{Discussion}

Labor analgesia has been evolved over the last years to minimize labor pain. Fentanyl have been used extensively intrathecally and epidurally for labor analgesia along with local anesthetics.
Table 2. Shows mode of delivery in the three groups.

\begin{tabular}{lllll}
\hline & $\begin{array}{l}\text { Group D } \\
\mathbf{n = 3 0}\end{array}$ & $\begin{array}{l}\text { Group F } \\
\mathbf{n = 3 0}\end{array}$ & $\begin{array}{l}\text { Group DF } \\
\mathbf{n = 3 0}\end{array}$ & P value \\
\hline $\begin{array}{l}\text { Vaginal delivery } \\
\text { (n, \%) }\end{array}$ & $20(66.7 \%)$ & $19(63.3 \%)$ & $19(63.3 \%)$ & $>0.05$ \\
$\begin{array}{l}\text { Assisted vacuum } \\
\text { vaginal delivery } \\
\text { (n, \%) }\end{array}$ & $6(20.0 \%)$ & $6(20.0 \%)$ & $6(20.0 \%)$ & $>0.05$ \\
C\&S (n, \%) due to: & $4(13.3 \%)$ & $5(16.7 \%)$ & $5(16.7 \%)$ & $>0.05$ \\
$\begin{array}{l}\text { Fetal distress } \\
\text { Failure of progress }\end{array}$ & 3 & 1 & 1 & $>0.05$ \\
\hline
\end{tabular}

Data presented as numbers (percentage)

Dexmedetomidine, is a highly selective a 2 adrenoreceptor agonist has been used in spinal and epidural anesthesia as an 


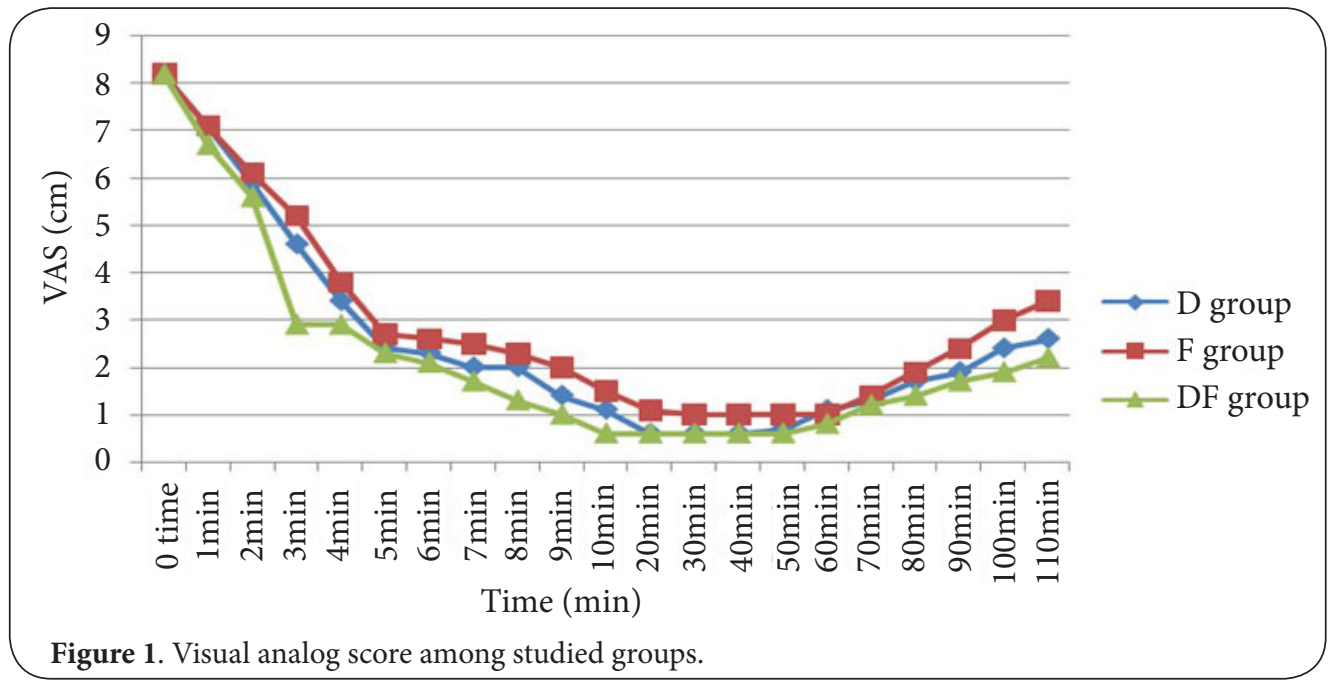

adjuvant to local anesthetics and has several advantages of increased duration of analgesia compared to local anesthetics alone with no adverse neurological effects [13].

Based on earlier human studies, it is hypothesized that intrathecal $5 \mu \mathrm{g}$ dexmedetomidine would produce more postoperative analgesic effect with hyperbaric bupivacaine in spinal anesthesia with minimal side effects $[14,15]$.

Our study used $5 \mu$ g dexmedetomidine plus $10 \mu \mathrm{g}$ fentanyl intrathecally in labor with minimal adverse effects on the mother or newborn were noted. In agree with our results, a recent study done by Niu et al., has shown that intrathecal dexmedetomidine prolonged the duration of spinal anesthesia and improved postoperative analgesia and did not increase the incidence of hypotension and adverse events [16].

The onset of analgesia with dexmedetomidine+fentanyl was faster than dexmedetomidine or fentanyl only. Duration of analgesia was better in group DF compared to groups $D$ and F. All patients achieved a VAS $<3$ after 5 minutes. The present study showed that addition of spinal $5 \mu \mathrm{g}$ dexmedetomidine to fentanyl significantly prolonged duration of analgesia compared with either use of intrathecal $20 \mu \mathrm{g}$ fentanyl or 10 $\mu \mathrm{g}$ dexmedetomidine.

Similar study, showed significantly improved analgesic efficacy was seen by Gupta et al., on comparison of dexmedetomidine and fentanyl as intrathecal adjuvant $(P<0.001)$ [3]. Al-Mustafa and Hala et al., observed dose dependent prolongation of duration of action of analgesia with reduced analgesic requirement when intrathecal dexmedetomidine dosages increased $(5,10$ and $15 \mu \mathrm{g})[15,17]$.

As regard to neonatal outcomes: Apgar scores (at1 and 5 minutes) and mean umbilical artery $\mathrm{pH}$ in all the groups were within normal values with the differences between the groups were not statistically significant $(P>0.05)$. Mahdy et al., found that after intrathecal dexmedetomidine and fentanyl injection there were no adverse effects on mothers or babies in any group [18]. Fyneface-Ogan et al., found no significant differences in the Apgar score, $\mathrm{pH}$ of umbilical venous blood, baseline fetal heart rate [19].

Most of the case reports and studies that described the use of dexmedetomidine in parturients have mentioned that babies delivered were with normal APGAR scores which proved that even if there is any uteroplacental transfer, it doesn't affect the fetal well-being [9-12].

Adverse effects in the form of hypotension and bradycardia were markedly observed in $D$ group than in the 2 other groups. Fyneface-Ogan et al., agreed with our results by observing minimal change of maternal blood pressure after intrathecal administration of dexmedetomidine. Clinical studies have demonstrated the safety of intrathecal dexmedetomidine in humans [21]. However it has been shown that dexmedetomidine in relatively high doses can lead to hypotension when administered either neuraxially or intravenously [14].

A lower dose $(5 \mu \mathrm{g})$ of dexmedetomidine was used in our study and the parturient remained hemodynamically stable. It is well known that intrathecal administration of local anesthetics reduce blood pressure by decreasing sympathetic outflow [22].

There is a published interesting case report about the successful use of dexmedetomidine $1 \mu \mathrm{g} / \mathrm{kg}$ followed by 1 $\mu \mathrm{g} / \mathrm{kg} / \mathrm{h}$ for 10 minutes before cesarean delivery to facilitate awake fiberoptic endotracheal intubation patient with spinal muscular atrophy type III with provided adequate sedation, without respiratory compromise [23].

Similarly, Palanisamy et al., used i.v. dexmedetomidine successfully as an adjunct to opioid-based PCA and general anesthesia for the respective provision of labor analgesia and cesarean delivery anesthesia in a parturient with a tethered spinal cord, with favorable maternal and neonatal outcome [11]. In our study, with the prolonged period of analgesia demonstrated by intrathecal dexmedetomidine+fentanyl, with lack of adverse effects (such as sedation, respiratory depression, hypotension in the mother, and neonatal depression) could 
Mohamed et al. Journal of Anesthesiology \& Clinical Science 2015, http://www.hoajonline.com/journals/pdf/2049-9752-4-1.pdf

be considered an attractive alternative for labor analgesia.

\section{Conclusion}

Our study concluded that Addition of $5 \mu \mathrm{g}$ intrathecal dexmedetomidine to $10 \mu \mathrm{g}$ fentanyl prolonged the duration of analgesia. The combination decreases the incidence of side effects in comparison to IT $10 \mu \mathrm{g}$ dexmedetomidine or IT 20 $\mu \mathrm{g}$ fentanyl alone.

\section{Study limitations}

Follow up newborn feeding and the effect of the study on breast feeding.

\section{Competing interests}

The authors declare that they have no competing interests.

Authors' contributions

\begin{tabular}{|l|c|c|}
\hline Authors' contributions & AAM & RAS \\
\hline Research concept and design & -- & $\checkmark$ \\
\hline Collection and/or assembly of data & $\checkmark$ & -- \\
\hline Data analysis and interpretation & $\checkmark$ & -- \\
\hline Writing the article & -- & $\checkmark$ \\
\hline Critical revision of the article & $\checkmark$ & -- \\
\hline Final approval of article & $\checkmark$ & -- \\
\hline Statistical analysis & -- & $\checkmark$ \\
\hline
\end{tabular}

Acknowledgement and funding

We would like to thank our colleagues in the Obstetrics \& Gynecology departments and department of Neonatology, Qena and Sohag university hospitals, South Valley and Sohag Universities \& Qena and Sohag university hospitals.

\section{Publication history}

EIC: D. John Doyle, Case Western Reserve University, USA.

Received: 16-May-2015 Final Revised: 17-Jun-2015

Accepted: 26-Jun-2015 Published: 04-Jul-2015

\section{References}

1. Dilesh PK, Eapen S, Kiran S and Chopra V. A comparison of intrathecal dexmedetomidine verses intrathecal fentanyl with epidural bupivacaine for combined spinal epidural labor analgesia. J Obstet Anaesth Crit Care. 2014; 4:69-74. | Article

2. Onah $\mathrm{HE}$, Obi SN, Oguanuo TC, Ezike HA, Ogbuokiri CM and Ezugworie JO. Pain perception among parturients in Enugu, South-eastern Nigeria. J Obstet Gynaecol. 2007; 27:585-8. | Article | PubMed

3. Gupta R, Verma R, Bogra J, Kohli M, Raman R and Kushwaha JK. A Comparative study of intrathecal dexmedetomidine and fentanyl as adjuvants to Bupivacaine. J Anaesthesiol Clin Pharmacol. 2011; 27:33943. | PubMed Abstract | PubMed Full Text

4. Mauro VA and Brandão ST. Clonidine and dexmedetomidine through epidural route for post-operative analgesia and sedation in a colecistectomy. Rev Bras Anestesiol. 2004; 4:1-10. | Article

5. Venn RM, Hell J and Grounds RM. Respiratory effects of dexmedetomidine in the surgical patient requiring intensive care. Crit Care. 2000; 4:302-8. | Article | PubMed Abstract | PubMed Full Text

6. Taghinia AH, Shapiro FE and Slavin SA. Dexmedetomidine in aesthetic facial surgery: improving anesthetic safety and efficacy. Plast Reconstr Surg. 2008; 121:269-76. | Article | PubMed

7. Ebert TJ, Hall JE, Barney JA, Uhrich TD and Colinco MD. The effects of increasing plasma concentrations of dexmedetomidine in humans.
Anesthesiology. 2000; 93:382-94. | Article | PubMed

8. Elbaradie S, El Mahalawy FH and Solyman AH. Dexmedetomidine vs. propofol for short-term sedation of postoperative mechanically ventilated patients. J Egypt Natl Canc Inst. 2004; 16:153-8. | Pdf | PubMed

9. Nair AS and Sriprakash K. Dexmedetomidine in pregnancy: Review of literature and possible use. J Obstet Anaesth Crit Care. 2013; 3:3-6. I Article

10. Abu-Halaweh SA, Al Oweidi AK, Abu-Malooh H, Zabalawi M, Alkazaleh F, Abu-Ali $\mathrm{H}$ and Ramsay MA. Intravenous dexmedetomidine infusion for labour analgesia in patient with preeclampsia. Eur J Anaesthesiol. 2009; 26:86-7. | Article | PubMed

11. Palanisamy A, Klickovich RJ, Ramsay M, Ouyang DW and Tsen LC. Intravenous dexmedetomidine as an adjunct for labor analgesia and cesarean delivery anesthesia in a parturient with a tethered spinal cord. Int J Obstet Anesth. 2009; 18:258-61. | Article | PubMed

12. Hanoura SE, Hassanin R and Singh R. Intraoperative conditions and quality of postoperative analgesia after adding dexmedetomidine to epidural bupivacaine and fentanyl in elective cesarean section using combined spinal-epidural anesthesia. Anesth Essays Res. 2013; 7:16872. | Article | PubMed Abstract | PubMed Full Text

13. Mahendru V, Tewari A, Katyal S, Grewal A, Singh MR and Katyal R. A comparison of intrathecal dexmedetomidine, clonidine, and fentanyl as adjuvants to hyperbaric bupivacaine for lower limb surgery: A double blind controlled study. J Anaesthesiol Clin Pharmacol. 2013; 29:496-502. | Article | PubMed Abstract | PubMed Full Text

14. Al-Ghanem SM, Massad IM and Al-Mustafa MM et al. Effect of adding dexmedetomidine versus fentanyl to intrathecal bupivacaine on spinal block characteristics in gynecological procedures: a double blind controlled study. Am J Appl Sci. 2009; 6:882-87. | Article

15. Al-Mustafa MM, Abu-Halaweh SA, Aloweidi AS, Murshidi MM, Ammari BA, Awwad ZM, Al-Edwan GM and Ramsay MA. Effect of dexmedetomidine added to spinal bupivacaine for urological procedures. Saudi Med J. 2009; 30:365-70. | Article | PubMed

16. Niu XY, Ding XB, Guo T, Chen MH, Fu SK and Li Q. Effects of intravenous and intrathecal dexmedetomidine in spinal anesthesia: a meta-analysis. CNS Neurosci Ther. 2013; 19:897-904. | Article | PubMed

17. Hala EA, Shafie MA and Youssef $H$. Dose related prolongation of hyperbaric bupivacaine spinal anesthesia by dexmedetomidine. Ain Shams J Anesthesiol. 2011; 4:83-95. | Pdf

18. Mahdy WR and Abdullah SI. Effect of adding dexmetomedine versus fentanyl to intrathecal bupivacaine on spinal block characteristics and neonatal outcome in uncomplicated cesarean delivary: A randomized double blind placebo controlled study. Menoufiya Medical Journal. 2011; 24:221-32.

19. Fyneface-Ogan S, Job OG and Enyindah CE. Comparative effects of single shot intrathecal bupivacaine with dexmedetomidine and bupivacaine with fentanyl on labor outcome. ISRN Anesthesiol. 2012. | Article

20. Adeyemi O, Vernon R and Medge O. A spinal labour analgesia protocol for Ghana, in Proceedings of the 4th All Africa Anaesthesia Congress. 2009; 67-68.

21. Weinbroum AA and Ben-Abraham R. Dextromethorphan and dexmedetomidine: new agents for the control of perioperative pain. Eur J Surg. 2001; 167:563-9. | PubMed

22. Neumann MM, Davio MB, Macknet MR and Applegate RL, 2nd. Dexmedetomidine for awake fiberoptic intubation in a parturient with spinal muscular atrophy type III for cesarean delivery. Int J Obstet Anesth. 2009; 18:403-7. | Article | PubMed

23. Imarengiaye $\mathrm{CO}$. Trends in pain relief in labour: implications for obstetric analgesia service in Nigeria. Niger Postgrad Med J. 2005; 12:193-202. | Article | PubMed

Citation:

Mohamed AA and Salem RA. Intrathecal dexmedetomidinefentanyl for labor analgesia: randomized comparative study. J Anesthesiol Clin Sci. 2015; 4:1.

http://dx.doi.org/10.7243/2049-9752-4-1 